\title{
Does hyperoxia enhance susceptibility to secondary pulmonary infection in the ICU?
}

\author{
Benedikt Nußbaum ${ }^{1,2}$, Peter Radermacher ${ }^{2^{*}}$, Pierre Asfar ${ }^{3,4}$ and Clair Hartmann ${ }^{1,2}$ \\ See related research by Six et al. http://www.ncbi.nlm.nih.gov/pmc/articles/PMC4917974/
}

\begin{abstract}
Hyperoxia is common practice in the acute management of circulatory shock, and observational studies report that it is present in more than $50 \%$ of mechanically ventilated patients during the first $24 \mathrm{~h}$ after intensive care unit (ICU) admission. On the other hand, "oxygen toxicity" due to the increased formation of reactive oxygen species limits its use due to serious deleterious side effects. However, formation of reactive oxygen species to boost bacterial killing is one of the body's anti-microbial auto-defense mechanisms and, hence, $\mathrm{O}_{2}$ has been referred to as an antibiotic. Consequently, hyperoxia during the peri-operative period has been advocated for surgical patients in order to reduce surgical site infection. However, there is ample evidence that long-term exposure to hyperoxia impaired bacterial phagocytosis and thereby aggravated both bacterial burden and dissemination. Moreover, a recent retrospective study identified the number of days with hyperoxia, defined as a $\mathrm{PaO}_{2}>120 \mathrm{mmHg}$ only, as an independent risk factor of ventilator-associated pneumonia in patients needing mechanical ventilation for more than $48 \mathrm{~h}$. Since so far the optimal oxygenation target is unknown for ICU patients, "conservative" $\mathrm{O}_{2}$ therapy represents the treatment of choice to avoid exposure to both hypoxemia and excess hyperoxemia.
\end{abstract}

Keywords: Hyperoxia, Mechanical ventilation, Antibiotic, Ventilator-associated pneumonia, Phagocytosis, Catecholamine, Sedation

\section{Background}

Despite recent evidence that "conservative" oxygenation targets are safe $[1,2]$, hyperoxia is frequently present in the intensive care unit (ICU) $[3,4] . \mathrm{O}_{2}$ has friend-andfoe properties because it is vital for ATP production and toxic due to its oxidant effects [5]. On the one hand, "... administration of oxygen should be started immediately to increase $\mathrm{O}_{2}$ delivery..." during the management of circulatory shock in order to counteract the pathognomonic "... imbalance between $\mathrm{O}_{2}$ supply and requirements..." [6]. On the other hand, oxygen toxicity arises from the formation of reactive oxygen species (ROS), in particular during hypoxia/re-oxygenation, e.g., during shock resuscitation. ROS themselves share the janus-headed character of $\mathrm{O}_{2}$ : they are vital signaling molecules and their increased release to boost bacterial killing is one of the body's antimicrobial auto-defense mechanisms [7]. ROS formation is

\footnotetext{
* Correspondence: peter.radermacher@uni-ulm.de

${ }^{2}$ Klinik für Anästhesiologie, Abteilung Klinische Anästhesiologie,

Universitätsklinikum, Albert-Einstein-Allee 23, Ulm, Germany

Full list of author information is available at the end of the article
}

directly related to the $\mathrm{PO}_{2}[5]$ and, hence, $\mathrm{O}_{2}$ was already described as an antibiotic three decades ago [5]. Again, there is contrasting experimental evidence: long-term (48-96 h) exposure to $\mathrm{PaO}_{2}$ values $>350-400 \mathrm{mmHg}$ aggravated the pulmonary bacterial burden and the bacteria dissemination [8] due to impaired bacterial phagocytosis and endotoxin-induced cytokine release. Interestingly, ROS scavengers dose-dependently restored the bactericidal capacity.

Hyperoxia during the peri-operative period was reported to reduce post-operative wound infection. Pure $\mathrm{O}_{2}$ ventilation attenuated the anesthesia- and surgeryinduced impairment of the phagocytic and microbicidal capacity of alveolar macrophages in healthy patients undergoing prolonged ( $>6$ up to $10 \mathrm{~h}$ ) elective surgery [9]. The most recent meta-analysis ( $>8000$ patients in 17 randomized control trials (RCTs)) concluded that hyperoxia significantly decreases the risk of surgical site infection during colorectal surgery [10]. Nevertheless, this approach remains highly controversial due to the "moderate evidence" [10] and the deleterious long-term complications 
reported in patients with cancer [11] and/or cardiovascular disease [12]. Moreover, the question remains unanswered whether hyperoxia affects host defense in mechanically ventilated ICU patients in general: using a multivariate analysis of retrospective data on patients needing mechanical ventilation for $>48 \mathrm{~h}$, Six et al. recently identified the number of days with hyperoxia as an independent risk factor of ventilator-associated pneumonia (VAP) [13].

\section{Hyperoxia, lung function, and $\mathrm{O}_{2}$ transport}

Hyperoxia impairs pulmonary gas exchange due to inhibition of hypoxic pulmonary vasoconstriction and adsorption atelectasis [5]. Moreover, under healthy conditions blood $\mathrm{O}_{2}$ content only modestly increases upon switching from air to pure $\mathrm{O}_{2}$ breathing due to the near-complete arterial hemoglobin $\mathrm{O}_{2}$ saturation $\left(\mathrm{SaO}_{2}\right)$ at $\mathrm{PaO}_{2}=90-100 \mathrm{mmHg}$ [5]. Hence, the lower the hemoglobin content, the more pronounced the effect of hyperoxia on blood $\mathrm{O}_{2}$ content, such that hyperoxia may be helpful during hemorrhage [5]. However, any hyperoxia-related rise in blood $\mathrm{O}_{2}$ content may at least in part be counterbalanced by a hyperoxiainduced fall in cardiac output resulting from decreased heart rate and increased systemic vascular resistance, the latter being particularly pronounced in the cerebral and coronary vasculature [5].

The acute hyperoxia-induced impairment of gas exchange must be discriminated from pulmonary $\mathrm{O}_{2}$ toxicity, which presents as pulmonary inflammation and, ultimately, hemorrhagic pulmonary edema [5]. This effect is wellestablished after long-term hyperoxic exposures and/or when combined with injurious ventilation. The only data in mechanically ventilated patients originate from hyperoxia over $14 \mathrm{~h}$ to 30 days and, given the publication year (1972), lung-protective ventilation most likely was not used [5].

\section{Hyperoxia and secondary pulmonary infection}

The study by Six et al. [13] clearly suggests an association between hyperoxia and VAP. Of note, hyperoxia was defined as a $\mathrm{PaO}_{2}>120 \mathrm{mmHg}$, in other words, a $\mathrm{PaO}_{2}$ that is commonly observed in ICU patients [3, 4]. Moreover, the authors showed not only that the numbers of days with hyperoxia, but also "hyperoxemia at ICU admission", in other words, deliberate, iatrogenic pre-ICU hyperoxia, was an independent risk factor of VAP. Clearly, patients with VAP were older, sicker, and, in particular, more frequently in shock prior to ICU admission. First, shock, as the dysbalance between tissue $\mathrm{O}_{2}$ supply and demand leads to tissue hypoxia, which in turn triggers hyper-inflammation that is aimed to clear pathogens [14]. However, when "too pronounced and/or sustained", tissue hypoxia may cause anti-inflammation, thereby rendering patients more susceptible to secondary infection [14]. Second, shock is defined as arterial hypotension and/or the need for vasopressor use. Hence, in the study by Six et al., patients with VAP most likely received catecholamines more frequently, for a longer period, and/or at higher doses. Exogenous catecholamines can impair both innate and adaptive immunity and thereby increase bacterial growth and virulence. Despite these potential limits and confounding factors, the study by Six et al. raises an important question with respect to the use of hyperoxia, i.e., whether there is an optimal $\mathrm{PaO}_{2}$ target in the ICU. So far, only retrospective data are available yielding a $\mathrm{U}$-shaped relationship between mortality and arterial $\mathrm{PO}_{2}$, with a nadir at $\mathrm{PaO}_{2}$ values of $110-150 \mathrm{mmHg}$ [3] and $150-200 \mathrm{mmHg}$ [15]. Mortality sharply increased at $\mathrm{PaO}_{2}<65 \mathrm{mmHg}$ and $>225 \mathrm{mmHg}$ [3]. However, another study found that even $\mathrm{PaO}_{2}>300 \mathrm{mmHg}$ did not affect outcome, while confirming the harmful impact of $\mathrm{PaO}_{2}<65 \mathrm{mmHg}$ [4]. Consequently, despite a strong signal suggesting an association between hyperoxia and poor hospital outcome, the most recent meta-analyses on hyperoxia $[16,17]$ are inconclusive due to the high data heterogeneity.

\section{Conclusions}

Hyperoxia is common practice during shock management based on experimental evidence that correcting oxygen debt is crucial for survival. On the other hand, oxygen toxicity limits its use, especially during hypoxia/ re-oxygenation and/or long-term administration (i.e., $>12-24$ h). The data of the RCT "Optimal Oxygenation in the Intensive Care Unit (O2-ICU)" (NCT02321072) comparing $\mathrm{PaO}_{2}$ targets of 120 versus $75 \mathrm{mmHg}$ in ICU patients and the detailed results of the preliminary terminated $2 \times 2$-factorial RCT "Hyperoxia and Hypertonic Saline in Septic Shock (Hyper2S)" (NCT01722422), simultaneously comparing target $\mathrm{SaO}_{2}$ 88-95 \% versus pure $\mathrm{O}_{2}$ ventilation during the first $24 \mathrm{~h}$ and isotonic versus hypertonic saline, are therefore eagerly awaited. The results may allow finding criteria for "...a personalized $\mathrm{O}_{2}$ target...in critically ill patients" [14]. Until then, conservative $\mathrm{O}_{2}$ therapy $[1,2]$ should be the treatment of choice to avoid both hypoxemia and excess hyperoxia.

\section{Abbreviations \\ $I C U$, intensive care unit; $R C T$, randomized controlled trial; ROS, reactive oxygen species; $\mathrm{SaO}_{2}$, arterial hemoglobin oxygen saturation; VAP, ventilator-associated pneumonia \\ Funding \\ PR was supported by the Deutsche Forschungsgemeinschaft (CRC1149, Project B03) and the German MoD (Vertragsforschungsvorhaben E/U2AD/CF523/DF556).}

Authors' contributions

All authors helped to draft the manuscript and read and approved the final manuscript.

Competing interests

The authors declare that they have no competing interests. 


\section{Author details}

Institut für Anästhesiologische Pathophysiologie und Verfahrensentwicklung, Universitätsklinikum, Helmholtzstrasse 8/1, Ulm, Germany. ${ }^{2}$ Klinik für Anästhesiologie, Abteilung Klinische Anästhesiologie, Universitätsklinikum, Albert-Einstein-Allee 23 , Ulm, Germany. ${ }^{3}$ Département de Réanimation Médicale et de Médecine Hyperbare, Centre Hospitalier Universitaire, 4 rue Larrey, Angers, France. ${ }^{4}$ Laboratoire de Biologie Neurovasculaire et Mitochondriale Intégrée, CNRS UMR 6214 - INSERM U1083, Université Angers, PRES L'UNAM, Angers 49933, Cedex 9, France.

\section{Published online: 16 August 2016}

\section{References}

1. Panwar R, Hardie M, Bellomo R, Barrot L, Eastwood GM, Young PJ, Capellier G, Harrigan PW, Bailey M, CLOSE Study Investigators, ANZICS Clinical Trials Group. Conservative versus liberal oxygenation targets for mechanically ventilated patients. A pilot multicenter randomized controlled trial. Am J Respir Crit Care Med. 2016;193:43-51.

2. Helmerhorst HJF, Schultz MJ, van der Voort PHJ, Bosman RJ, Juffermans NP, de Wilde RBP, van den Akker-van MArle ME, van Bodegom-Vos $L$, de Vries M, Eslami S, de Keizer NF, Abu-Hanna A, van Westerloo DJ, de Jonge E. Effectiveness and clinical outcome of a two-step implementation of conservative oxygenation targets in critically ill patients: a before and after trial. Crit Care Med. 2016;44:554-63.

3. de Jonge $E$, Peelen L, Keijzers PJ, Joore $H$, de Lange D, van der Voort $\mathrm{PH}$, Bosman RJ, de Waal RAL, Wesselink R, de Keizer NF. Association between administered oxygen, arterial partial oxygen pressure and mortality in mechanically ventilated intensive care unit patients. Crit Care. 2008;12:R156.

4. Eastwood G, Bellomo R, Bailey M, Taori G, Pilcher D, Young P, Beasley R. Arterial oxygen tension and mortality in mechanically ventilated patients. Intensive Care Med. 2012;38:91-8.

5. Hafner S, Beloncle F, Koch A, Radermacher P, Asfar P. Hyperoxia in intensive care, emergency, and peri-operative medicine: Dr. Jekyll or Mr. Hyde? A 2015 update. Ann Intensive Care. 2015;5:42.

6. Vincent JL, De Backer D. Circulatory shock. N Engl J Med. 2013;369:1726-34.

7. Magder S. Reactive oxygen species: toxic molecules or spark of life? Crit Care. 2006;10:208.

8. Patel VS, Sampat V, Espey MG, Sitapara R, Wang H, Yang X, Ashby Jr CR, Thomas DD, Mantell LL. Ascorbic acid attenuates hyperoxia-compromised host defense against pulmonary bacterial infection. Am J Respir Cell Mol Biol. 2016. doi:10.1165/rcmb.2015-03100C [Epub ahead of print]

9. Kotani N, Hashimoto H, Sessler DI, Muraoka M, Hashiba E, Kubota T, Matsuki A. Supplemental intraoperative oxygen augments antimicrobial and proinflammatory responses of alveolar macrophages. Anesthesiology. 2000;93:15-25.

10. Yang W, Liu Y, Zhang Y, Zhao QH, He SF. Effect of intra-operative high inspired oxygen fraction on surgical site infection: a meta-analysis of randomized controlled trials. J Hosp Infect. 2016. doi:10.1016/j.jhin.2016.03.015 [Epub ahead of print].

11. Meyhoff CS, Jorgensen LN, Wetterslev J, Siersma VD, Rasmussen LS, PROXI Trial Group. Risk of new or recurrent cancer after a high perioperative inspiratory oxygen fraction during abdominal surgery. Br J Anaesth. 2014;113 Suppl 1:i74-81.

12. Fonnes S, Gögenur I, Søndergaard ES, Siersma VD, Jorgensen LN, Wetterslev J, Meyhoff CS. Perioperative hyperoxia-long-term impact on cardiovascular complications after abdominal surgery, a post hoc analysis of the PROXI trial. Int J Cardiol. 2016;215:238-43.

13. Six S, Jaffal K, Ledoux $G$, Jaillette E, Wallet F, Nseir S. Hyperoxemia as a risk for ventilator-associated pneumonia. Crit Care. 2016;20:195.

14. Kiers HD, Scheffer GJ, van der Hoeven JG, Eltzschig HK, Pickkers P, Kox M. Immunologic consequences of hypoxia during critical illlness. Anesthesiology. 2016. doi:10.1097/ALN.0000000000001163 [Epub ahead of print].

15. Helmerhorst HJ, Roos-Blom MJ, van Westerloo DJ, Abu-Hanna A, de Keizer $N F$, de Jonge E. Associations of arterial carbon dioxide and arterial oxygen concentrations with hospital mortality after resuscitation from cardiac arrest. Crit Care. 2015;19:348.

16. Damiani E, Adrario E, Girardis M, Romano R, Pelaia P, Singer M. Arterial hyperoxia and mortality in critically ill patients: a systematic review and meta-analysis. Crit Care. 2014;18:711.

17. Helmerhorst HJF, Roos-Blom MJ, van Westerloo DJ, de Jonge E. Association between arterial hyperoxia and outcome in subsets of critical illness: a systematic review, metaanalysis, and meta-regression of cohort studies. Crit Care Med. 2015;43:1508-19. 